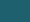

\title{
RESEARCH
}

\section{Interleukin-2 drives cortisol secretion in an age-, dose-, and body composition-dependent way}

\author{
Ferdinand Roelfsema', Peter Y Liư ${ }^{2}$, Rebecca Yang ${ }^{3}$, Paul Takahashi ${ }^{4}$ and Johannes D Veldhuis ${ }^{3}$ \\ 1Department of Internal Medicine, Section Endocrinology, Leiden University Medical Center, Leiden, The Netherlands \\ 2Department of Medicine, David Geffen School of Medicine at UCLA, Harbor-UCLA Medical Center and Los Angeles Biomedical Research Institute, \\ Los Angeles, California, USA \\ ${ }^{3}$ Endocrine Research Unit, Mayo Clinic College of Medicine, Center for Translational Science Activities, Mayo Clinic, Rochester, Minnesota, USA \\ ${ }^{4}$ Primary Care Internal Medicine, Mayo Clinic, Rochester, Minnesota, USA
}

Correspondence should be addressed to J D Veldhuis: veldhuis.johannes@mayo.edu

\section{Abstract}

Background: Interleukin-2 (IL-2), one of the proinflammatory cytokines, is used in the treatment of certain malignancies. In some studies, transient increases in cortisol and ACTH secretion occurred. Thus, this agent may be used as an experimental probe of adrenal cortisol secretion.

Objective: This study quantifies the effects of low and moderate doses of IL-2 on cortisol secretion and assesses the modulation by age, dose and body composition.

Site: Mayo Clinical Translational Research Unit.

Subjects: Study comprised 35 healthy men, 17 young and 18 older.

Methods: Randomized prospective double-blind saline-controlled study of IL-2

administration in two doses with concurrent 10-min blood sampling for $24 \mathrm{~h}$.

Outcome measures: Deconvolution analysis and approximate entropy of cortisol secretion.

Results: Low-dose IL-2 administration increased nocturnal pulsatile cortisol secretion from $1460 \pm 160$ to $2120 \pm 220 \mathrm{nmol} / \mathrm{L} / 8 \mathrm{~h}$ in young subjects and from $1680 \pm 105$ to $1960 \pm 125 \mathrm{nmol} / \mathrm{L} / 8 \mathrm{~h}$ (treatment $P<0.0001$, but more in young than older, $P=0.02$ ). Comparable results were obtained for total cortisol secretion ( $P$ treatment $<0.0001$, age effect $P=0.005)$. The higher IL-2 dose caused a large increase in young $(P<0.0001)$, but not in older $(P=0.90)$ subjects. This dose also increased approximate entropy from $0.877 \pm 0.041$ to $1.024 \pm 0.049(P=0.008)$, pointing to reduced secretory orderliness. Incremental cortisol (nocturnal) secretion correlated negatively with visceral fat mass $(R=-0.41, P=0.019)$.

Conclusion: In healthy men, IL-2 injection drives pulsatile cortisol secretion in a dosedependent way in young, but not older, individuals and erodes cortisol secretory orderliness at a higher dose in young subjects. Cortisol responses are diminished with increasing abdominal visceral fat mass.

\section{Key Words}

- cytokines

- interleukin

- inflammation

- adrenal

- cortisol https://ec.bioscientifica.com

https://doi.org/10.1530/EC-20-0211 (c) 2020 The authors Published by Bioscientifica Ltd

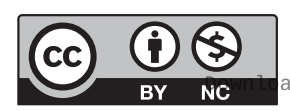

This work is licensed under a Creative Commons Attribution-NonCommercial 4.0 International License. ded from Bioscientifica.com at 04/26/2023 08:29:18AM
Endocrine Connections

(2020) 9, 637-648 


\section{Introduction}

Systemic inflammation due to cytokine activation is associated with varying degrees of hypothalamopituitary-adrenal activation as part of the stress response to infection, burns, trauma, critical illness, autoimmune diseases, and sleep disorders (1). At present, the precise extent to which specific inflammatory mediators mediate hypercortisolemia is unknown. This is pertinent because the cytokine family of immunoregulators has many members that include interleukins (IL-1 to IL-21), tumor necrosis factors (TNF), interferons, chemokines, colony stimulating factors, neutrophins and other growth factors. The wide-ranging effects of systemic inflammation on metabolic health, sleep, reproduction, and other fundamental biological processes raises the possibility that at least some of these interactions could be mediated through neuroendocrine pathways $(1,2,3)$.

IL-2 is a prime candidate for study because it was one of the first factors discovered to regulate $\mathrm{T}$ cells and induce inflammation (3); it is used clinically as an anti-tumor drug for renal carcinoma and melanoma, and as immunotherapy for HIV infection by promoting activation of the cytotoxic (killer) T cell population (4); and preliminary studies indicate that it may be useful as an immuno-neuroendocrine probe of adrenal function (5). Nonetheless, virtually all studies were uncontrolled and performed in patients with advanced cancer, in whom cortisol responses differ from those of healthy men (5). In addition, only few (generally hourly) blood samples were withdrawn, which limits the assessment of the time course of response, and IL-2 was administered by either the i.v. or i.m. route. The present study was therefore designed to address this knowledge deficit. This focus complements the earlier study of IL-2's suppressive effect on the gonadotropic axis in the same cohort of volunteers (6).

Aging is also associated with increased systemic inflammation (7) and regulation of the HPA axis is age dependent. With advancing age, serum cortisol concentrations during the evening and early night increase, together with an advance (earlier) shift in the timing of maximal secretion $(8,9)$. In addition, negative feedback inhibition of ACTH by cortisol in the elderly is diminished $(10,11)$, thus leading to increased or more prolonged overall cortisol secretion after a stimulus. Analogously, ACTH and cortisol responses to the combined dexamethasone-corticotropin-releasing hormone (CRH) test are amplified in the elderly (12). The HPA-axis hyperactivity in aging is partially refractory to stimulation by mineralocorticoid receptor blockade, pointing to central activation of the HPA axis in aging $(13,14)$. In addition, several studies have shown that ACTH secretion is greater with increasing BMI, while the adrenal gland is less responsive to ACTH $(15,16,17)$. Importantly, the impact of age on the magnitude of the IL-2 effect on the HPA axis is unknown. We hypothesized that IL-2 administration, as an inflammatory model, could mediate heightened cortisol responses in older subjects compared with younger subjects, and be altered by increased visceral fat mass.

The present randomized placebo-controlled crossover study comprised s.c. injection of recombinant human (rh)IL-2 (Proleukin, Novartis Vaccines and Diagnostics, Inc., NY, USA $)$ in two different doses $\left(3 \times 10^{6} \mathrm{IU} / \mathrm{m}^{2}\right.$ and $\left.6 \times 10^{6} \mathrm{IU} / \mathrm{m}^{2}\right)$ and quantification of the amount, pattern and regularity of the 24 -h cortisol secretion in young and older men subjected to intensive blood sampling.

\section{Methods}

\section{Overview}

The design was a prospectively randomized, double-blind placebo-controlled crossover study, evaluating the impact of experimental IL-2-induced inflammatory stress on cortisol secretion in young and older men. Each subject underwent two overnight studies in the Mayo Clinical Translational Research Unit (CRU) to receive injections of either 3 million ( $n=6$ young, $n=6$ older) or 6 million ( $n=11$ young, $n=12$ older) IU of rhIL- 2 compared with saline. IL-2 was obtained as Proleukin from Novartis Pharmaceuticals, under an individual investigatorinitiated new drug investigation number, lodged with the United States Food and Drug Administration (FDA). To monitor cortisol secretion, blood was withdrawn every 10 min for $24 \mathrm{~h}$ starting $2 \mathrm{~h}$ before the injection. The weight amount of $1.1 \mathrm{mg}$ IL-2 corresponds with 18 million IU. Figure 1 outlines schematically the study.

Inclusion criteria were healthy men ages 18-30 and 60-80 years recruited from Rochester, Olmsted County, $\mathrm{MN}$, and surrounding catchment areas by flyers, radio and newspaper ads, and Web-based advertisements. Volunteers provided witnessed, signed, informed and Mayo Institutional Review Board (IRB)-approved consent, and underwent a screening history and physical examination to identify acute or chronic organ-level disease. Screening biochemical tests of liver, kidney, hematological, and metabolic disease were negative.

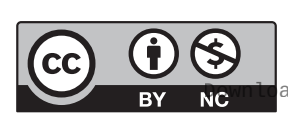

This work is licensed under a Creative Commons Attribution-NonCommercial 4.0 International License. ded from Bioscientifica.com at 04/26/2023 08:29:18AM 


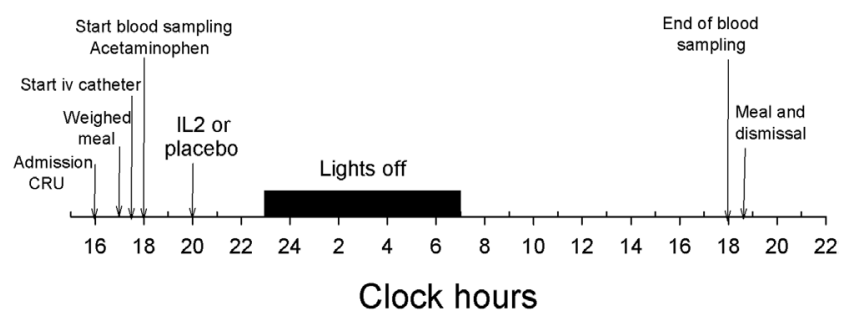

Figure 1

Schematic outline of the experimental protocol. The order of the drug administration (IL-2 vs placebo) was randomly assigned. Blood sampling at 10 min intervals started $18: 00 \mathrm{~h}$ and ended at $18: 00 \mathrm{~h}$ next day. The first six young and six older subjects received saline or 3 million IU of IL-2 $\mathrm{sc}$, for safety assessment, and the last 11 young and 12 older men received 6 million IU at 20:00 h or placebo. Meals were served at 17:00 $\mathrm{h}$ on the first day and 18:15 h on the next day. At the start of blood sampling all subjects received $650 \mathrm{mg}$ acetaminophen orally. The black box indicates the period of lights off.

Exclusions comprised individuals unable or unwilling to provide written informed consent secondary to cognitive decline, mental illness, institutionalization or imprisonment. Volunteers with a history of cardiovascular illness, abnormal ECG on screening, cancer, sleep apnea, chronic obstructive pulmonary disease, hematological dyscrasias, acute or chronic inflammatory conditions, renal insufficiency, hepatic failure, and chronic infections (e.g. hepatitis or HIV) were also excluded. Subjects receiving medications (prescription or over-the-counter) were excluded with the exception of replacement thyroid hormone, laxatives, antacids, thiazide diuretics, ophthalmic solutions or skin preparations. Other exclusions were recent use of glucocorticoids (3 months), non-steroidal anti-inflammatory drugs (10 days), chronic drug or alcohol abuse, major psychiatric illness, weight gain or loss ( $>2 \mathrm{~kg} / 2$ months), or transmeridian travel (over 3 time zones) within last 10 days. In this group of volunteers, we have studied the effect of IL- 2 on the gonadotrope axis and the results of that study have been published (6).

\section{Detailed protocol}

Volunteers were admitted to the Clinical Research Unit (CRU) at 16:00 h for placement of bilateral forearm iv catheters. To limit possible nutritional confounds, a vegetarian or non-vegetarian standardized meal $(8 \mathrm{kcal} / \mathrm{kg}$ of $50 \%$ carbohydrate, $20 \%$ protein and $30 \%$ fat) was served at 17:00 $\mathrm{h}$, and again at 18:00 $\mathrm{h}$ the next day. Subjects remained alcohol-abstinent and caffeine-free. At 17:30 $\mathrm{h}$ an i.v. catheter was inserted. Some subjects received topical lidocaine to facilitate the procedure. Beginning at 18:00 $\mathrm{h}$, blood was sampled every $10 \mathrm{~min}$ for $24 \mathrm{~h}(2.7$
$\mathrm{mL} /$ sample) until 18:00 h on day 2 . At the outset, a single $1 \mathrm{~mL}$ archival serum sample was obtained for safetymonitoring purposes, and subjects were given $650 \mathrm{mg}$ of acetaminophen orally for antipyresis. Two hours later $(20: 00 \mathrm{~h})$, men received a single sc injection of saline or IL-2. The first six young and six older subjects received saline or 3 million IU of IL-2 sc once for safety assessment, and the last 11 young and 12 older men received 6 million IU in accordance with FDA-negotiated guidelines. Inpatient CRU sessions were scheduled at least 3 weeks, but no more than 2 months apart. Abdominal visceral fat (AVF) and total abdominal fat (TAF) were obtained from single-slice CT at L4-L5 and the surface area was expressed in square $\mathrm{cm}$.

\section{Assays}

Cortisol was measured by a competitive binding immunoenzymatic assay on the DxI automated immunoassay system (Beckman Instruments, Chaska, $\mathrm{MN}$, USA). Intra-assay CVs are $13.1 \%, 9.4 \%$, and $6.6 \%$ at 43,79 and $833 \mathrm{nmol} / \mathrm{L}$, respectively. Inter-assay CVs are 9.0\%, $8.1 \%$, and $9.3 \%$ at 68,477 and $759 \mathrm{nmol} / \mathrm{L}$, respectively. The lower limit of the assay is $11 \mathrm{nmol} / \mathrm{L}$ (Beckman Coulter Cat. No. 33600, RRID: AB_2802133). IL-2 was measured with a Human IL-2 Quantikine HS ELISA kit. The sensitivity was $0.066 \mathrm{ng} / \mathrm{L}$, intraassay precision $2 \%$, interassay precision 5.8\% (R\&D Systems; CAT No. HS200 Part 898670, RRID: AB_2813830). Other screening measures were performed in the Mayo Clinical Laboratory.

\section{Subject risks and protection}

The risks of the iv sampling were stated as anemia, localized phlebitis, swelling, redness or bruising. Reported risks for IL-2 included malaise, fever and headache commonly, and hypotension, oliguria, or capillary-leak syndrome rarely $(18,19,20,21)$. There was a possibility of an immune response in the form of blocking antibodies to IL-2 (22). Thus, requirements by the FDA were starting $\mathrm{Hb}>8 \mathrm{mmol} / \mathrm{L}$, maintenance of archival serum, and follow-up blood count and liver enzymes 3-10 days after study visits. Safety data were reviewed by the FDA, Mayo Data Safety Monitoring Board, Mayo IRB and National Institute for Aging.

\section{Deconvolution analysis}

Cortisol concentration time series were analyzed using an automated deconvolution method, 
which was empirically validated using hypothalamopituitary sampling and simulated pulsatile time series $(23,24)$. Sensitivity and specificity both exceed $93 \%$. In brief, multiparameter deconvolution analysis is a test instrument intended to estimate secretory burst frequency, amplitude, mass, and duration, as well as hormone half-life according to a particular a priori model of hormone secretion and clearance from serial hormone concentrations, here 8 -h or 24 -h 10-min blood samples.

The Matlab-based algorithm first detrends the data and normalizes concentrations to the unit interval $[0,1]$. Second, the program creates multiple successively decremental potential pulse-onset time sets, each containing one fewer burst by a smoothing process (a nonlinear adaptation of the heat-diffusion equation). Third, a maximum-likelihood expectation (MLE) estimation method calculates all secretion and elimination parameters simultaneously conditional on each of the candidate pulse-time sets. Deconvolution parameters comprise basal secretion, secretory-burst mass, random effects on burst mass, procedural/measurement error, the mode (time delay to maximum value) of the secretoryburst waveform, secretory burst frequency (number of bursts per sampling duration (lambda of Weibull distribution), pulsatile secretion (sum of secretory-burst mass), and total (sum of basal plus pulsatile) secretion. The fast half-life of cortisol was represented as $2.41 \mathrm{~min}$ constituting $37 \%$ of the decay amplitude. The slow halflife of cortisol was estimated. Statistical model selection was performed using the Akaike information criterion. The parameters (and units) are total, basal and pulsatile secretion rates (concentration units/session), number of secretory bursts, mass secreted per burst (concentration units), and waveform mode (min). Both model-based and non-model-based parameters were calculated for the entire 24-h period as well as during the 8-h nocturnal period from 23:00 $\mathrm{h}$ to 07:00 $\mathrm{h}$.

Approximate Entropy (ApEn) is a scale- and modelindependent univariate regularity statistic used to quantify the orderliness (subpattern consistency) of serial stationary (nontrending) measurements. Higher ApEn defines reduced regularity of hormone secretion, which in general typifies puberty, aging, diminished negative feedback due to target-gland failure, fixed exogenous stimulation, and autonomous neuroendocrine tumors $(25,26)$. The statistic is calculated on a time series as a single, finite, positive, real number (between 0 and 2.3 in log base10 data).

\section{Statistics}

Data are shown as mean and s.E.M. Comparisons among the four experimental arms and their possible interactions were done with the General Linear Mode (GLM)l for repeated measurements. Time-shifts of the serum concentration curves were quantified by exponential regression analysis, while slopes were calculated by linear regression of the linear part of the concentration curve. The area under the curve (AUC) was calculated with the trapezoidal method. Calculations were performed with Systat version 13 (Systat Software, Inc, San Jose, CA, USA) and with Matlab (MathWorks, Natick, MA, USA). $P<0.05$ was construed as statistically significant.

\section{Results}

\section{Adverse events}

Adverse events were mild. Headache was reported in 2/35 control sessions and 3/35 IL-2 sessions. Mild flu-like symptoms of myalgia were more common after IL-2 than saline, especially after high-dose IL-2. No serious adverse events occurred, and all 35 subjects completed both 24-h study sessions.

\section{Base line studies}

Table 1 summarizes epidemiologic, clinical, and biochemical characteristics of the 35 volunteers. Six young and 6 older subjects received saline and low-dose IL-2 (3 million IU) (required by the FDA and IRB to verify safety), and an additional 11 young and 12 older men received saline and high dose IL-2 (6 million IU0. Body composition differed by age stratum, reflecting higher AVF in older men. Additionally, lower testosterone and IGF-I were found in older men. Fasting insulin, cortisol, TSH and $\mathrm{E}_{2}$ did not differ by age at screening.

\section{Deconvolution analysis}

Table 2 shows the results of the deconvolution of the complete 24-h serum cortisol concentration series, stratified for age (old/young) and treatment (Il-2/placebo). IL-2 increased cortisol pulse frequency and pulsatile cortisol secretion and with borderline increase in total (basal plus pulsatile) cortisol secretion.

Inspection of the 24-h concentration plots, displayed in Fig. 2, (young $v s$ older (Fig. 2A and B), placebo vs IL-2 
Table 1 Demographic variables before randomization.

\begin{tabular}{l}
\hline \\
\hline Age $(\mathrm{y})$ \\
$\operatorname{BMI}\left(\mathrm{kg} / \mathrm{m}^{2}\right)$ \\
$\operatorname{AVF}\left(\mathrm{cm}^{2}\right)$ \\
$\operatorname{TAF}\left(\mathrm{cm}^{2}\right)$ \\
$\mathrm{Hb}(\mathrm{nmol} / \mathrm{L})$ \\
Albumin $(\mathrm{g} / \mathrm{L})$ \\
TSH (mU/L) \\
Testosterone (nmol/L) \\
Estradiol (pmol/L) \\
IGF-1 (nmol/L) \\
IGFBP-3 (mg/L) \\
Insulin (mU/L) \\
Cortisol (nmol/L) \\
IL-2 (ng/L) \\
\hline
\end{tabular}

\begin{tabular}{c}
\hline Young/low \\
\hline $24 \pm 0.9$ \\
$26 \pm 1.3$ \\
$65 \pm 10$ \\
$261 \pm 69$ \\
$8.7 \pm 0.2$ \\
$46 \pm 0.9$ \\
$2.5 \pm 0.36$ \\
$20.3 \pm 1.4$ \\
$74 \pm 5.1$ \\
$25.1 \pm 2.4$ \\
$4.3 \pm 0.44$ \\
$29 \pm 4.3$ \\
$203 \pm 36$ \\
$13.1 \pm 2.5$
\end{tabular}

\begin{tabular}{c}
\hline Young/high \\
\hline $24 \pm 1.0$ \\
$25 \pm 0.8$ \\
$79 \pm 23$ \\
$229 \pm 47$ \\
$9.9 \pm 0.1$ \\
$48 \pm 0.4$ \\
$2.1 \pm 0.34$ \\
$18.1 \pm 1.6$ \\
$42 \pm 5.1$ \\
$25.8 \pm 1.1$ \\
$4.4 \pm 0.23$ \\
$32 \pm 6.9$ \\
$201 \pm 49$ \\
$28.1 \pm 12.7$ \\
\hline
\end{tabular}

\begin{tabular}{c}
\hline Older/low \\
\hline $64 \pm 1.6$ \\
$27 \pm 0.8$ \\
$173 \pm 37$ \\
$357 \pm 62$ \\
$8.7 \pm 0.2$ \\
$42 \pm 0.1$ \\
$3.1 \pm 0.58$ \\
$16.1 \pm 1.7$ \\
$61 \pm 6.6$ \\
$15.8 \pm 2.9$ \\
$4.1 \pm 0.50$ \\
$40 \pm 14.7$ \\
$122 \pm 13$ \\
$19.8 \pm 3.1$ \\
\hline
\end{tabular}

\begin{tabular}{c}
\hline Older/high \\
\hline $64 \pm 1.2$ \\
$28 \pm 1.2$ \\
$174 \pm 22$ \\
$414 \pm 72$ \\
$9.3 \pm 0.2$ \\
$42 \pm 0.8$ \\
$2.8 \pm 0.37$ \\
$14.4 \pm 0.9$ \\
$67 \pm 4.0$ \\
$16.1 \pm 1.1$ \\
$3.8 \pm 0.29$ \\
$52 \pm 10.8$ \\
$233 \pm 39$ \\
$31.5 \pm 5.1$ \\
\hline
\end{tabular}

\begin{tabular}{|c|c|}
\hline Age $P$-value & Dose P-value \\
\hline$<0.0001$ & 0.53 \\
\hline 0.049 & 0.32 \\
\hline$<0.0001$ & 0.78 \\
\hline 0.017 & 0.85 \\
\hline 0.12 & 0.002 \\
\hline$<0.0001$ & 0.31 \\
\hline 0.18 & 0.42 \\
\hline 0.01 & 0.20 \\
\hline 0.30 & 0.026 \\
\hline$<0.0001$ & 0.83 \\
\hline 0.21 & 0.88 \\
\hline 0.17 & 0.49 \\
\hline 0.60 & 0.24 \\
\hline 0.60 & 0.17 \\
\hline
\end{tabular}

Data are the mean \pm S.E.M. Low and high refer to subsequent randomization strata, low- or high-dose IL-2 vs saline injection. IGFBP, insulin-like growth factor binding protein. With the exception of insulin, which was measured in a 24-h serum pool, all other determinations were done in a fasting blood sample. Data were analyzed with GLM. The interaction factor age $\times$ dose was not significant in the analyses, except for estradiol.

AVF, abdominal visceral fat; TAF, total abdominal fat.

(Fig. 2C and D)) suggested that the main changes in serum cortisol concentration occurred a few hours after IL-2 administration at 20:00 $\mathrm{h}$. Therefore, the time intervals between the start of blood sampling (at 18:00 h) and start of the lights off period (at 23:00 h) and between 07:00 $\mathrm{h}$ until the end of sampling at 18:00 $\mathrm{h}$, were analyzed by calculating the AUC's (area under the curves), but no differences were detected. For the evening AUC's, neither age (young $v s$ older) nor treatment (IL-2 vs placebo) were significantly different ( $P=0.84$ and 0.50 , respectively). Comparable results were obtained for day-time AUC's ( $P$ values, age $P=0.68$, treatment $P=0.74$ ). Hence, these results justified the strategy to restrict the main analysis to the $8 \mathrm{~h}$ nocturnal period (23:00 $\mathrm{h}$ to $07: 00 \mathrm{~h}$ ).

Irrespective of the dose used, IL-2 caused a highly significant rise in cortisol concentrations, both in older and young subjects, here quantified by the AUC during the nocturnal time period. Age and IL-2 dose were not significant covariates. The increment of the cortisol after IL-2 was similar in the four conditions, depicted in Fig. 3.

\section{Nocturnal cortisol secretion}

Deconvolution analysis of the 8-h nocturnal time data series yielded the results depicted in Fig. 4A, B, C, D and Table 3. IL-2 administration caused an increase in pulse frequency, and a slight increase in half-life of cortisol in the older subjects, but not in the younger cohort. Basal (nonpulsatile) cortisol secretion remained unchanged after IL-2 administration, whereas pulsatile cortisol secretion increased significantly in both age groups, but more so in young subjects. Total secretion, the sum of basal

Table 2 Deconvolution of the 24-h serum cortisol concentration time series in placebo- and IL-2 treated young and older volunteers.

\begin{tabular}{|c|c|c|c|}
\hline & Young placebo & Young IL-2 & Old plac \\
\hline $\begin{array}{l}\text { Pulse frequency } \\
\text { (no/24 h) }\end{array}$ & $14.4 \pm 0.6$ & $16.8 \pm 0.9$ & $15.1 \pm$ \\
\hline Half-life (min) & $61.0 \pm 2.2$ & $58.2 \pm 2.2$ & $62.8 \pm$ \\
\hline $\begin{array}{l}\text { Basal secretion } \\
(\mathrm{nmol} / \mathrm{L} / 24 \mathrm{~h})\end{array}$ & $860 \pm 127$ & $960 \pm 130$ & $933 \pm$ \\
\hline $\begin{array}{l}\text { Pulsatile secretion } \\
\text { (nmol/L/24 h) }\end{array}$ & $3970 \pm 340$ & $4220 \pm 110$ & $3370 \pm 2$ \\
\hline $\begin{array}{l}\text { Total secretion } \\
(\mathrm{nmol} / \mathrm{L} / 24 \mathrm{~h})\end{array}$ & $4830 \pm 430$ & $5190 \pm 270$ & $4300 \pm$ \\
\hline $\begin{array}{l}\text { Mean pulse mass } \\
(\mathrm{nmol} / \mathrm{L})\end{array}$ & $281 \pm 25$ & $257 \pm 17$ & $226 \pm$ \\
\hline \multicolumn{4}{|c|}{ Data are mean \pm S.E.M. Statistical analysis was done with the GLM 2-way ANOV } \\
\hline \multicolumn{2}{|c|}{$\begin{array}{l}\text { https://ec.bioscientifica.com } \\
\text { https://doi.org/10.1530/EC-20-0211 }\end{array}$} & \multicolumn{2}{|c|}{$\begin{array}{l}\text { (c) } 2020 \text { The authors } \\
\text { Published by Bioscientifica Ltd }\end{array}$} \\
\hline
\end{tabular}

\begin{tabular}{|c|c|c|c|}
\hline OId IL-2 & $\begin{array}{c}\text { Treatment } \\
\text { P-value }\end{array}$ & $\begin{array}{c}\text { Age } \\
\text { P-value }\end{array}$ & $\begin{array}{c}\text { Interaction } \\
\text { P-value }\end{array}$ \\
\hline $18.8 \pm 1.8$ & $<0.0001$ & 0.059 & 0.51 \\
\hline $62.8 \pm 1.8$ & 0.49 & 0.12 & 0.44 \\
\hline $1029 \pm 143$ & 0.39 & 0.56 & 0.93 \\
\hline $4000 \pm 250$ & 0.027 & 0.25 & 0.33 \\
\hline $5020 \pm 330$ & 0.05 & 0.41 & 0.47 \\
\hline $212 \pm 11$ & 0.33 & 0.014 & 0.67 \\
\hline
\end{tabular}


Twenty four-hour Serum Cortisol Concentration Profiles
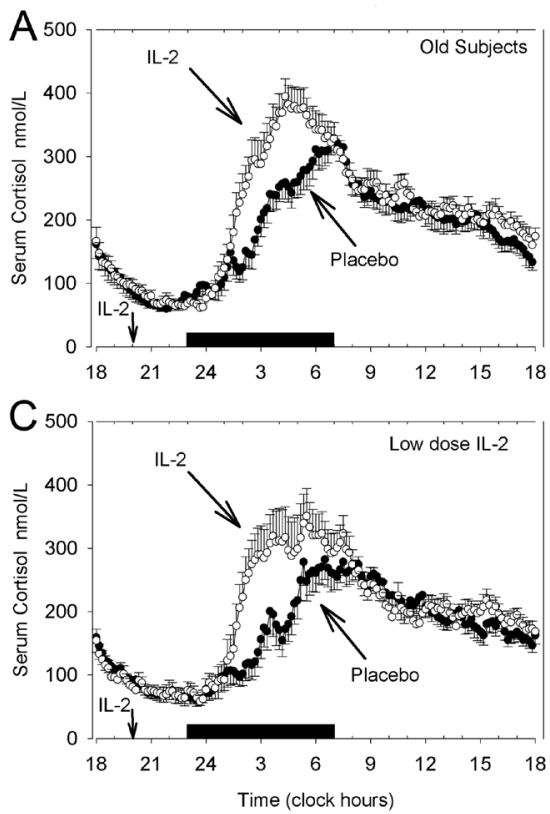
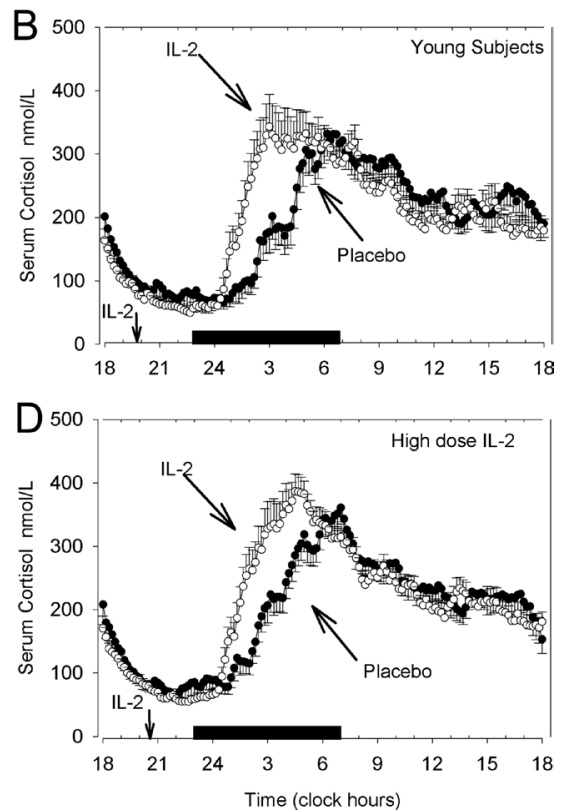

Figure 2

Serum cortisol concentration profiles obtained by sampling blood every $10 \mathrm{~min}$ for $24 \mathrm{~h}$. Data are shown as mean \pm S.E.M. The arrow on the X-axis indicates the time of administration of IL-2 or placebo. The black box indicates the period of lights off. In the upper two panels young and older subjects are compared, while in the lower two panels low-dose IL-2 is compared with high-dose administration. Open symbols indicate IL-2 administration and closed symbols indicate placebo treatment. and pulsatile secretion, increased especially in the young group. In young volunteers, the high IL-2 dose caused a greater increase in pulsatile and total cortisol secretion then in older subjects ( $P$ values 0.001 and $<0.0001$ ), but no difference in basal secretion $(P=0.58)$. The IL-2 dose was unrelated to the effect on basal, pulsatile and total cortisol secretion in older men $(P$ values $0.98,0.90$ and 0.87, respectively). Figure $2 \mathrm{~A}, \mathrm{~B}, \mathrm{C}$ and D also suggested an earlier rise in cortisol levels in the dark period of IL-2-treated subjects. The shift was quantified by logistic regression, as listed in Tables 4 and 5. The magnitude

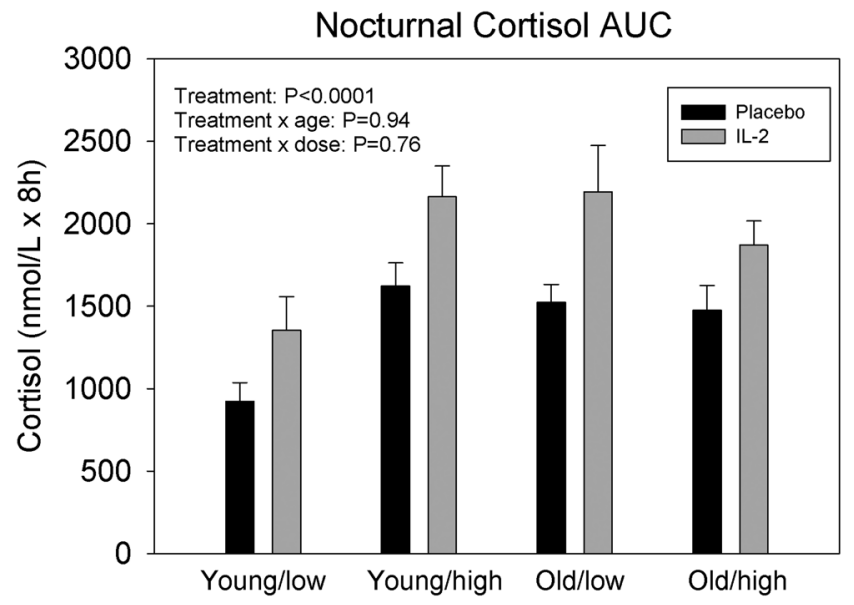

Figure 3

Effect of IL-2 administration on the area under the curve (AUC) for nocturnal cortisol concentrations in 35 healthy subjects, stratified by age (young and older) and IL-2 dose (low and high). Two-way generalized linear models (GLM) were used in the statistical analysis. of the time shift was the difference between the EC50's, here indicating the time at which $50 \%$ of the maximum concentration was reached. The time shift caused by IL-2 treatment was significant in young and older subjects, and also for both low and high dose IL-2 administration.

Other than the earlier rise (advanced time shift) of the cortisol concentration curves after IL-2 administration, the profiles during the period with lights off appeared to be steeper. The slopes were quantified by calculating the increase of the concentrations during the linear part. Results are shown in Table 6. Cortisol-time slopes increased during IL-2 exposure, indicating steeper slopes over placebo.

\section{Body composition}

Nocturnal pulsatile and total cortisol secretory increments were negatively related to body composition parameters, as depicted in Fig. 5A and B for abdominal visceral fat area, determined by CT scan. Comparable results were found for total (intraabdominal plus s.c.) abdominal fat area (Fig. 5C and D). Furthermore, BMI was negatively related to nocturnal incremental cortisol secretion after IL-2 challenge (for pulsatile secretion non-significantly, $P=0.14$, and significantly for total secretion, $P=0.022$ ).

\section{Approximate entropy}

ApEn of nocturnal cortisol release did not increase after low-dose IL-2 administration (0.981 \pm 0.099 to

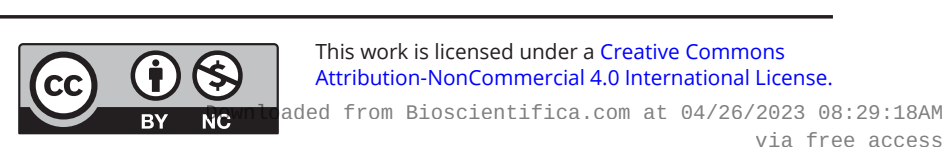


Deconvolution of Nocturnal Cortisol Secretion
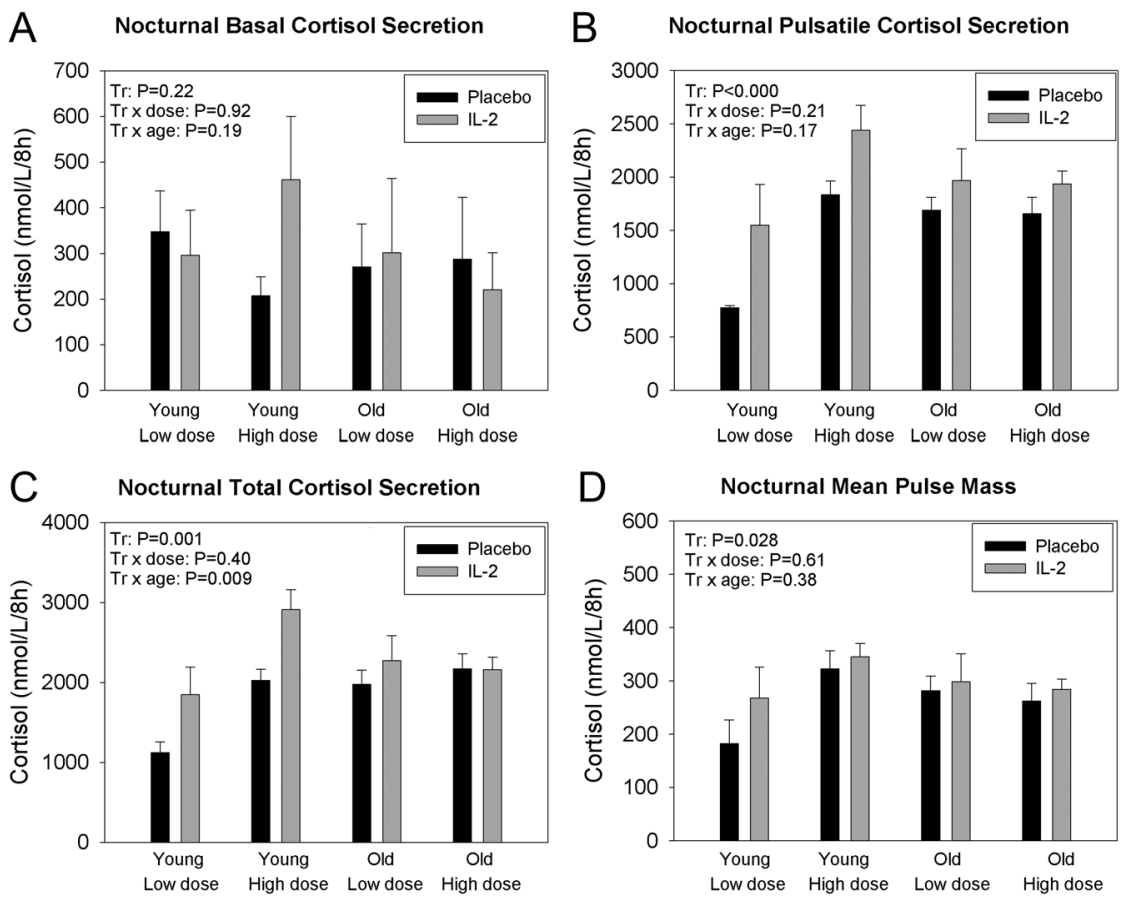
Figure 4
Nocturnal cortisol secretion quantified by deconvolution analysis of the 8-h concentration profiles. Data show the effects of IL-2 administration in the 4 cohorts. Bars represent the mean and S.E.M. GLM was used for statistical analysis, where age and IL-2 dose were categorical variables.

$0.991 \pm 0.046, P=0.92)$, but did in the high-dose group $(0.877 \pm 0.041$ to $1.024 \pm 0.049, P=0.008)$. ApEn increment denotes more random patterns, which did not correlate with body composition (AVF, TAF and BMI) or age.

\section{Serum IL2 levels}

IL-2 concentrations were measured in a single 24 -h serum pool. The mean concentration was larger in the high dose group than in the low-dose group $(23.8 \pm 3.3 \mathrm{ng} / \mathrm{L}$ vs $16.4 \pm 2.2 \mathrm{ng} / \mathrm{L}, P=0.035$ one-sided test). IL-2 levels were uncorrelated with age or body composition parameters.

Table 3 Deconvolution of the 8-h serum cortisol concentration series in placebo- and IL2-treated young and older volunteers during the period with lights off.

\begin{tabular}{|c|c|c|c|c|c|c|c|}
\hline & Young placebo & Young IL-2 & Old placebo & Old IL-2 & Tr P-value & $\begin{array}{l}\text { Tr } \times \text { Age } \\
\text { P-value }\end{array}$ & $\begin{array}{c}\text { Tr } \times \text { Dose } \\
\text { P-value }\end{array}$ \\
\hline $\begin{array}{l}\text { Pulse } \\
\text { frequency } \\
\text { (no/24 h) }\end{array}$ & $5.5 \pm 0.4$ & $6.9 \pm 0.6$ & $6.6 \pm 0.5$ & $7.1 \pm 0.5$ & 0.04 & 0.32 & 0.77 \\
\hline Half-life (min) & $60.3 \pm 2.7$ & $57.1 \pm 3.1$ & $56.6 \pm 2.8$ & $66.0 \pm 1.4$ & 0.20 & 0014 & 0.85 \\
\hline $\begin{array}{c}\text { Basal secretion } \\
\text { (nmol/L/8 h) }\end{array}$ & $250 \pm 44$ & $400 \pm 97$ & $420 \pm 97$ & $250 \pm 77$ & 0.22 & 0.08 & 0.96 \\
\hline $\begin{array}{l}\text { Pulsatile } \\
\text { secretion } \\
\text { (nmol/L/8 h) }\end{array}$ & $1460 \pm 160$ & $2125 \pm 220$ & $1670 \pm 105$ & $1950 \pm 130$ & $<0.0001$ & 0.02 & 0.22 \\
\hline $\begin{array}{l}\text { Total secretion } \\
\text { (nmol/L/8 h) }\end{array}$ & $1710 \pm 140$ & $2530 \pm 230$ & $2095 \pm 135$ & $2200 \pm 140$ & $<0.0001$ & 0.005 & 0.40 \\
\hline $\begin{array}{l}\text { Mean pulse } \\
\text { mass (nmol/L) }\end{array}$ & $273 \pm 30$ & $317 \pm 25$ & $268 \pm 22$ & $290 \pm 22$ & 0.028 & 0.38 & 0.43 \\
\hline
\end{tabular}

Data are mean \pm S.E.M. Statistical analysis was done with the GLM 3-way (treatment, age and dose) analysis for repeat measurements. Secretion data were logarithmically transformed.

Tr, treatment, IL-2 or placebo.

$\begin{array}{lr}\text { https://ec.bioscientifica.com } & \text { (c) } 2020 \text { The authors } \\ \text { https://doi.org/10.1530/EC-20-0211 } & \text { Published by Bioscientifica Ltd }\end{array}$

\section{Discussion}

This prospectively randomized, placebo-controlled blinded cross-over study aimed at quantifying the 
Table 4 Four-parameter logistic regressions of the mean serum cortisol concentrations on time during low and high IL-2 dose and placebo treatment.

\begin{tabular}{|c|c|c|c|c|c|}
\hline & Placebo & IL-2 & $\boldsymbol{R}^{2}$ (plac/II-2) & $t$-value & P-value \\
\hline Low IL-2 dose & & & $0.95 / 0.96$ & & \\
\hline Minimum (nmol/L) & $76 \pm 5$ & $75 \pm 5$ & & 0.23 & 0.40 \\
\hline Maximum (nmol/L) & $281 \pm 10$ & $320 \pm 4$ & & 5.56 & 0.001 \\
\hline EC50 (h) & $4.65 \pm 0.17$ & $2.13 \pm 0.04$ & & 25.2 & 0.001 \\
\hline High IL-2 dose & & & $0.95 / 0.99$ & & \\
\hline Minimum (nmol/L) & $88 \pm 7$ & $57 \pm 4$ & & 5.80 & 0.001 \\
\hline Maximum (nmol/L) & $321 \pm 7$ & $397 \pm 8$ & & 9.92 & 0.001 \\
\hline EC50 (h) & $3.71 \pm 0.12$ & $2.68 \pm 0.05$ & & 11.4 & 0.001 \\
\hline
\end{tabular}

Data are shown as mean and s.D. The $t$-test was two-sided, $t$-values from Documenta Geigy Wissenschafliche Tabellen, J R Geigy, S.A. Basle, Switzerland, 1960.

age- and dose-related increase of cortisol secretion in healthy men after a single s.c. injection of IL-2. Main outcomes of the study are that Il-2 evoked greater pulsatile cortisol secretion, and more so in young than in older subjects during the 8-hour nocturnal period. In addition, the higher vs low IL-2 dose in young subjects caused greater cortisol secretion, whereas such a dose-dependent effect was absent in older subjects. Furthermore, in older and young subjects, IL-2-driven cortisol secretion exhibited an advance (earlier) time shift, accompanied by accelerated secretion, as evidenced by the steeper slope. Finally, higher intra-abdominal fat mass diminished the cortisol response.

Many studies of IL-2 administration were performed in patients with advanced cancer or immunodeficiency syndrome. In these studies, IL-2 was generally injected iv which increased plasma ACTH and serum cortisol concentrations $(19,27,28,29,30,31)$, Mastorakos, 1993 \#182. Generally, only a few blood samples were taken, so that no detailed analysis was performed. In addition to patients with underlying serious, often fatal disease, lowdose IL-2 has been administered sc to healthy men in two studies, utilizing 1000 and 10,000 IU/kg body weight (18) or a total dose of 3 million IU irrespective of body weight (5). The lower sc 10,000 IU/kg dose (roughly 3-4 times less than the low-dose employed in the current study) given at 19:00 $\mathrm{h}$ increased serum IL-2 from a very low concentration to more than $120 \mathrm{ng} / \mathrm{L} 3 \mathrm{~h}$ after administration, but did not alter circulating concentrations of ACTH, cortisol and $\mathrm{GH}$, while TSH rose unexpectedly during the night. However, the 3 million IU dose in the other study increased cortisol concentrations progressively over an 8 -h period (during which blood was sampled every $2 \mathrm{~h}$ ). Collectively, these data with ours indicate that IL-2 activates the HPA-axis unequally by age in healthy men with strong dynamic effects on cortisol secretion.

Cytokines display a great overlap in biological activities (32). Activation of the HPA-axis in men is achieved by IL-2 and other interleukins, for example, IL-1 and IL-6 (33, $34,35)$. Mechanistic data are available in experimental animals studied in vitro and by direct infusion into the brain indicating that IL- $1 \alpha$ and IL- $1 \beta$, IL- 2 and IL- 6 activate neuronal CRH synthesis in hypothalamic PVN neurons, resulting in pituitary ACTH stimulation $(33,34,35,36$, $37,38,39,40)$. In addition to the CRH-dependent ACTH stimulation, disclosed by animal studies, other reports suggest a direct stimulating effect on the corticotrope by cytokines, which may function as an amplifier of the CRH effect (41), Arzt, 1992 \#179. Furthermore, cytokines may enhance glucocorticoid secretion via a direct

Table 5 Logistic regressions of the mean serum cortisol concentrations in young and old subjects.

\begin{tabular}{|c|c|c|c|c|c|}
\hline & Placebo & IL-2 & $\boldsymbol{R}^{\mathbf{2}}$ (Plac/IL-2) & $t$-value & P-value \\
\hline Young subjects & & & $0.91 / 0.97$ & & \\
\hline Minimum (nmol/L) & $96 \pm 10$ & $64 \pm 6$ & & 4.17 & 0.001 \\
\hline Maximum (nmol/L) & $286 \pm 10$ & $316 \pm 3$ & & 4.44 & 0.001 \\
\hline EC50 (h) & $2.60 \pm 0.16$ & $2.16 \pm 0.05$ & & 4.40 & 0.001 \\
\hline Old subjects & & & $0.98 / 0.99$ & & \\
\hline Minimum (nmol/L) & $82 \pm 4$ & $66 \pm 6$ & & 3.53 & 0.005 \\
\hline Maximum (nmol/L) & $366 \pm 20$ & $459 \pm 25$ & & 4.02 & 0.005 \\
\hline EC50 (h) & $5.01 \pm 0.26$ & $2.67 \pm 0.17$ & & 10.63 & 0.001 \\
\hline
\end{tabular}

Data are shown as mean and S.D. The $t$-test was two-sided, $t$-values from Documenta Geigy Wissenschafliche Tabellen, J R Geigy, S.A. Basle, Switzerland, 1960.

https://ec.bioscientifica.com

https://doi.org/10.1530/EC-20-0211 (c) 2020 The authors Published by Bioscientifica Ltd

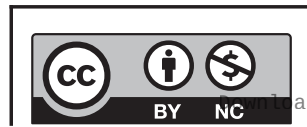

This work is licensed under a Creative Commons Attribution-NonCommercial 4.0 International License. ded from Bioscientifica.com at 04/26/2023 08:29:18AM via free access 
Table 6 Linear regression slopes of the nocturnal increase in cortisol concentrations.

\begin{tabular}{|c|c|c|c|}
\hline Group & Slope & $R^{2}$ & P-value; placebo vs IL-2 \\
\hline Young placebo & $1.40 \pm 0.13$ & 0.73 & $<0.0001$ \\
\hline Young IL-2 & $3.76 \pm 0.11$ & 0.98 & \\
\hline Old placebo & $1.27 \pm 0.04$ & 0.96 & $<0.0001$ \\
\hline Old IL-2 & $3.28 \pm 0.15$ & 0.98 & \\
\hline
\end{tabular}

Data are shown as mean and s.D. Statistical differences were assessed with the two-sided Student's $t$-test.

adrenal effect, as demonstrated in hypophysectomized rats and in primary adrenal cell cultures $(41,42,43)$. The direct cytokine effect on the adrenals may serve as a continuing stimulus of glucorticoid secretion after the ACTH signal has diminished (44).

In the present analysis in healthy men, IL-2 administration was followed by a time lag of several hours before cortisol secretion increased, in contrast to other CRF-ACTH stimuli, including insulin-induced hypoglycemia. The time lag might be dependent on the slow release from the injection site into the circulation, but also on the time needed for the IL-2 signal to reach PVN nuclei. Cytokines are hydrophilic proteins, which cannot easily cross the blood-brain barrier (BBB), unless the BBB is damaged by for example, tumor, inflammation, cerebral-vascular accident or trauma. Available data suggest that for IL- signal transduction to the PVN eicosanoids, viz., prostaglandins act as mediators $(45,46,47)$.

Cortisol secretion during the 8-h nocturnal period (from 23:00 to $07: 00 \mathrm{~h}$ ) increased by $45 \%$ in young and only by $16 \%$ in older subjects. Thus, HPA-axis stimulability by IL-2 seems less in older subjects. This inference complements observations in which a higher dose of IL-2 was needed to stimulate a cortisol response in individuals with cancer versus healthy controls (5). Whereas in young subjects doubling the IL-2 dose was associated with a greater cortisol secretion, this dosing effect was absent in older subjects. We hypothesize that a maximal stimulatory effect of IL-2 may be reached at a lower dose in older subjects, which could worsen frailty in aging individuals. More detailed research employing dose-response analysis is needed in this area. The observed age-dependent difference in cortisol response to IL-2 cannot be attributed to eventual differences in late evening cortisol concentrations, which were comparable in the groups (mean concentration between 20-23 h: $70 \pm 8.6 \mathrm{nmol} / \mathrm{L}$ in older subjects and $71 \pm 5.6 \mathrm{nmol} / \mathrm{L}$ in young volunteers, $P=0.91$ ).

Another possibility that needs to be further investigated is whether the strong effect of IL-2 on nocturnal cortisol

\section{Regressions of incremental nocturnal cortisol secretion and body composition} after low dose and high dose IL-2.
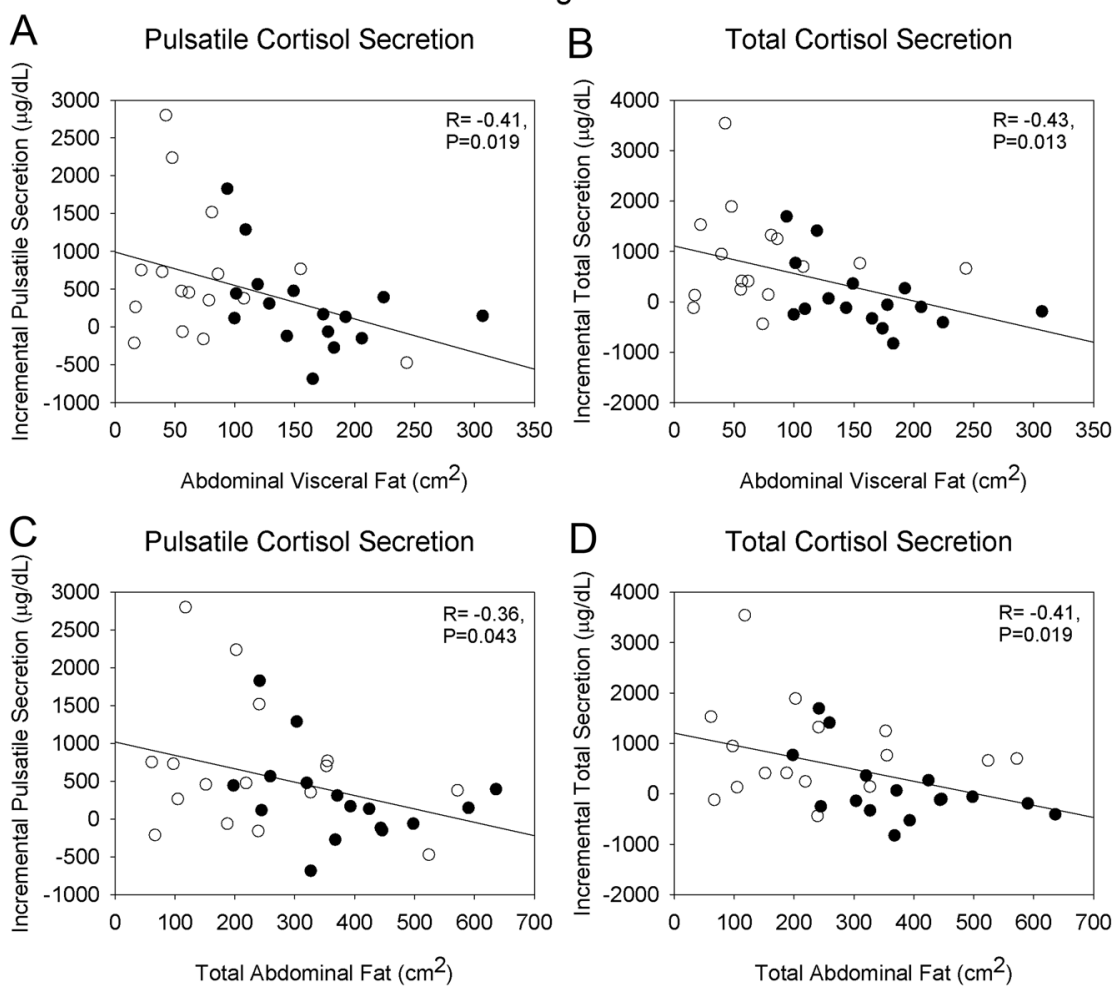

\section{Figure 5}

Linear regression plots relating nocturnal incremental pulsatile and total cortisol secretion and body composition parameters. Open circles designate low dose and closed circles high dose IL-2 administration. https://ec.bioscientifica.com https://doi.org/10.1530/EC-20-0211 (c) 2020 The authors Published by Bioscientifica Ltd

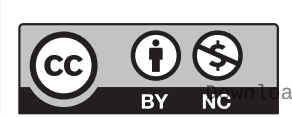

This work is licensed under a Creative Commons Attribution-NonCommercial 4.0 International License. ded from Bioscientifica.com at 04/26/2023 08:29:18AM via free access 
secretion is modulated by sleep. This is possible, because sleep enhances immune responses, certain cytokines promote sleep, and the HPA neuroendocrine pathway connects sleep with the immune system (1). Under these circumstances, systemic inflammation acting through HPA activation in an age-modified manner could confer a mechanism by which sleep loss impairs neurobehavioral, as well as metabolic and putatively reproductive health in aging (48).

The earlier nocturnal rise in cortisol secretion likely reflects the timing of IL-2 administration rather than resetting of the circadian rhythm. Further experiments that manipulate the timing of IL-2 administration will be required to resolve this consideration. In our study, IL-2 not only increased cortisol secretion, but actually also accelerated secretion for a relatively short period. In older subjects this overall phenomenon was accompanied by a decrease in secretion burst-mode, indicating that within each pulse maximal secretion was attained at an earlier time. The mechanistic basis of this observation is not known at present.

Under the high IL-2 dose, cortisol ApEn increased, signifying a less regular secretion pattern. This finding is compatible with a heightened central drive by CRH on the HPA axis, rather than diminished feedback at the pituitary and/or hypothalamic level. Controlled CRH infusions in healthy men under clamping of cortisol (as feedback signal) increases ACTH secretory disorderliness; conversely, glucocorticoid receptor blockade, as well as direct inhibition of cortisol secretion by metyrapone or ketoconazole, all decrease ACTH ApEn $(49,50)$. Thus, in contrast with other pituitary regulatory systems, for example, the growth hormone axis and the gonadotropic axis, where decreased feedback increases ApEn, the HPA axis reacts quite differently in this respect. A mechanistic explanation for increased ACTH secretory regularity when negative feedback is muted might involve co-modulation of ACTH release by somatostatin or other hypothalamic factors (49).

Cortisol secretion quantified by deconvolution analysis of 24-h profiles sampled at 10-min intervals do not correlate with BMI (9), although ACTH secretion is amplified in obesity, suggesting diminished adrenal responsivity to ACTH (17). The finding here of less IL2induced cortisol secretion with increasing abdominal fat (visceral and total fat area) would also be compatible with diminished adrenal responsiveness to ACTH (or other peptides). However, this postulate does not exclude a comparable mechanism at central sites. In addition, cortisol secretion in adiposity is increased while serum levels are either unchanged or slightly diminished, pointing to increased plasma clearance $(51,52)$. Thus, increased cortisol clearance rate might contribute to the observed visceral fat-related decreased IL-2 response.

IL-2 is used as antitumor agent in renal cell cancer and melanoma, either alone or in combination with other anticancer drugs, such as kinase and immune checkpoint inhibitors $(53,54)$. In many patients, severe side effects were noted at higher doses than used here. Thus, current phase III trials in melanoma no longer use IL-2, except in one study (53). Our finding that the cortisol response is rather short lived and limited, especially in older subjects, may tend to restrict any catabolic effect in this age group.

There are several limitations in this study. First, we investigated only two doses of IL-2 and exploring lower doses in future studies could be informative on the doseresponse relation; second, IL-2 was given in the evening, but whether the cortisol response would comparable at other time points is unknown; third, whether cortisol responses remain similar after repeated administration is unknown; fourth, due to funding restrictions of this complicated study, we have no data on ACTH secretion, but even if these data were available it would be impossible to state how much of the ultimate effect of IL-2 on cortisol secretion could be attributed to $\mathrm{CRH}$, and direct effects on the corticotrope and adrenal gland, and fifth, this study cannot be extrapolated to healthy premenopausal and postmenopausal women, or to children.

In summary, IL-2 administration in healthy men, as a paradigm for inflammation, evokes definite by a relatively short-lived increased cortisol secretion, larger in young than in older subjects, and larger at a higher dose, only in young volunteers. Increasing abdominal visceral and total fat was associated with attenuated cortisol secretion.

\section{Declaration of interest}

The authors declare that there is no conflict of interest that could be perceived as prejudicing the impartiality of the research reported.

\section{Funding}

Supported in part via R01 AG019695, R01 AG029362, and P30 DK050456 (Metabolic Studies Core of the Minnesota Obesity Center) from the National Institutes of Health (Bethesda, MD). The project described was supported by UL1 TR000135 from the National Center for Advancing Translational Sciences (NCATS).

\section{Additional information}

The data sets generated during and/or analyzed during the current study are not publicly available but are available from the corresponding author on reasonable request. 


\section{Acknowledgments}

The authors thank the Mayo Immunochemical Laboratory for assay assistance; and the Mayo research nursing staff for implementing the protocol. Contents are solely the responsibility of the authors and do not necessarily represent the official views of any federal institution. Matlab versions of ApEn and deconvolution methodology are available from Veldhuis.johannes@mayo.edu.

\section{References}

1 Irwin MR. Sleep and inflammation: partners in sickness and in health. Nature Reviews Immunology 201919 702-715. (https://doi. org/10.1038/s41577-019-0190-z)

2 Mani SK. Neuroendocrine regulation of reproduction, stress, inflammation and energy homeostasis. Journal of Neuroendocrinology 201830 e12648. (https://doi.org/10.1111/jne.12648)

3 Ross SH \& Cantrell DA. Signaling and function of interleukin-2 in T lymphocytes. Annual Review of Immunology 201836 411-433. (https://doi.org/10.1146/annurev-immunol-042617-053352)

4 Gaffen SL \& Liu KD. Overview of interleukin-2 function, production and clinical applications. Cytokine 200428 109-123. (https://doi. org/10.1016/j.cyto.2004.06.010)

5 Lissoni P, Messina G, Brivio F, Rovelli F, Di Fede G, Mainini E \& Veronese E. Cortisol response to an acute injection of IL-2 in healthy subjects and cancer patients: a first immunoneuroendocrine standardized clinical test to explore the interactions between immune and neuroendocrine systems. Journal of Biological Regulators and Homeostatic Agents 200519 141-144.

6 Veldhuis J, Yang R, Roelfsema F \& Takahashi P. Proinflammatory cytokine infusion attenuates LH's feedforward on testosterone secretion: modulation by age. Journal of Clinical Endocrinology and Metabolism 2016101 539-549. (https://doi.org/10.1210/jc.20153611)

7 Hagen M \& Derudder E. Inflammation and the alteration of B-cell physiology in aging. Gerontology 201966 1-9.

8 Deuschle M, Gotthardt U, Schweiger U, Weber B, Korner A, Schmider J, Standhardt H, Lammers CH \& Heuser I. With aging in humans the activity of the hypothalamus-pituitary-adrenal system increases and its diurnal amplitude flattens. Life Sciences 199761 2239-2246. (https://doi.org/10.1016/S0024-3205(97)00926-0)

9 Roelfsema F, van Heemst D, Iranmanesh A, Takahashi P, Yang R \& Veldhuis JD. Impact of age, sex and body mass index on cortisol secretion in 143 healthy adults. Endocrine Connections 20176 500-509. (https://doi.org/10.1530/EC-17-0160)

10 Boscaro M, Paoletta A, Scarpa E, Barzon L, Fusaro P, Fallo F \& Sonino N. Age-related changes in glucocorticoid fast feedback inhibition of adrenocorticotropin in man. Journal of Clinical Endocrinology and Metabolism 199883 1380-1383.

11 Wilkinson CW, Petrie EC, Murray SR, Colasurdo EA, Raskind MA \& Peskind ER. Human glucocorticoid feedback inhibition is reduced in older individuals: evening study. Journal of Clinical Endocrinology and Metabolism 200186 545-550.

12 Hatzinger M, Brand S, Herzig N \& Holsboer-Trachsler E. In healthy young and elderly adults, hypothalamic-pituitary-adrenocortical axis reactivity (HPA AR) varies with increasing pharmacological challenge and with age, but not with gender. Journal of Psychiatric Research 2011 45 1373-1380. (https://doi.org/10.1016/j.jpsychires.2011.05.006)

13 Giordano R, Bo M, Pellegrino M, Vezzari M, Baldi M, Picu A, Balbo M, Bonelli L, Migliaretti G, Ghigo E \& Arvat E. Hypothalamuspituitary-adrenal hyperactivity in human aging is partially refractory to stimulation by mineralocorticoid receptor blockade. Journal of Clinical Endocrinology and Metabolism 200590 5656-5662. (https:// doi.org/10.1210/jc.2005-0105)
14 Heuser IJ, Gotthardt U, Schweiger U, Schmider J, Lammers CH, Dettling M \& Holsboer F. Age-associated changes of pituitaryadrenocortical hormone regulation in humans: importance of gender. Neurobiology of Aging 199415 227-231. (https://doi. org/10.1016/0197-4580(94)90117-1)

15 Kok P, Kok SW, Buijs MM, Westenberg JJ, Roelfsema F, Frolich M, Stokkel MP, Meinders AE \& Pijl H. Enhanced circadian ACTH release in obese premenopausal women: reversal by short-term acipimox treatment. American Journal of Physiology: Endocrinology and Metabolism 2004287 E848-E856.

16 Roelfsema F, Kok P, Frolich M, Pereira AM \& Pijl H. Disordered and increased adrenocorticotropin secretion with diminished adrenocorticotropin potency in obese in premenopausal women. Journal of Clinical Endocrinology and Metabolism 200994 2991-2997. (https://doi.org/10.1210/jc.2009-0350)

17 Roelfsema F, Pijl H, Keenan DM \& Veldhuis JD. Diminished adrenal sensitivity and ACTH efficacy in obese premenopausal women. European Journal of Endocrinology 2012167 633-642. (https://doi. org/10.1530/EJE-12-0592)

18 Lange T, Marshall L, Spath-Schwalbe E, Fehm HL \& Born J. Systemic immune parameters and sleep after ultra-low dose administration of IL-2 in healthy men. Brain, Behavior, and Immunity 200216 663-674. (https://doi.org/10.1016/S0889-1591(02)00018-1)

19 Raab C, Weidmann E, Schmidt A, Bergmann L, Badenhoop K, Usadel KH \& Haak T. The effects of interleukin-2 treatment on endothelin and the activation of the hypothalamic-pituitary-adrenal axis. Clinical Endocrinology 199950 37-44. (https://doi.org/10.1046/ j.1365-2265.1999.00592.x)

20 Sundin DJ \& Wolin MJ. Toxicity management in patients receiving low-dose aldesleukin therapy. Annals of Pharmacotherapy 199832 1344-1352. (https://doi.org/10.1345/aph.18019)

21 Sundin DJ \& Wolin MJ. Aldesleukin therapy in HIV-infected patients. American Journal of Health-System Pharmacy 199855 1520-1523. (https://doi.org/10.1093/ajhp/55.14.1520)

22 Tsigos C, Papanicolaou DA, Kyrou I, Raptis SA \& Chrousos GP. Dose-dependent effects of recombinant human interleukin-6 on the pituitary-testicular axis. Journal of Interferon and Cytokine Research 199919 1271-1276. (https://doi.org/10.1089/107999099312948)

23 Keenan DM, Roelfsema F, Biermasz N \& Veldhuis JD. Physiological control of pituitary hormone secretory-burst mass, frequency, and waveform: a statistical formulation and analysis. American Journal of Physiology: Regulatory, Integrative and Comparative Physiology 2003285 R664-R673.

24 Liu PY, Keenan DM, Kok P, Padmanabhan V, O’Byrne KT \& Veldhuis JD. Sensitivity and specificity of pulse detection using a new deconvolution method. American Journal of Physiology: Endocrinology and Metabolism 2009297 E538-E544. (https://doi.org/10.1152/ ajpcell.00248.2009)

25 Pincus SM. Approximate entropy as a measure of system complexity. PNAS 199188 2297-2301. (https://doi.org/10.1073/pnas.88.6.2297)

26 Veldhuis JD \& Pincus SM. Orderliness of hormone release patterns: a complementary measure to conventional pulsatile and circadian analyses. European Journal of Endocrinology 1998138 358-362. (https://doi.org/10.1530/eje.0.1380358)

27 Atkins MB, Gould JA, Allegretta M, Li JJ, Dempsey RA, Rudders RA, Parkinson DR, Reichlin S \& Mier JW. Phase I evaluation of recombinant interleukin-2 in patients with advanced malignant disease. Journal of Clinical Oncology 19864 1380-1391. (https://doi. org/10.1200/JCO.1986.4.9.1380)

28 Chambrier C, Mercatello A, Tognet E, Cottet-Emard JM, Cohen R, Blay JY, Favrot M, Philip T \& Beylot M. Hormonal and metabolic effects of chronic interleukin-2 infusion in cancer patients. Journal of Biological Response Modifiers 19909 251-255.

29 Lissoni P, Barni S, Archili C, Cattaneo G, Rovelli F, Conti A, Maestroni GJ \& Tancini G. Endocrine effects of a 24-hour https://ec.bioscientifica.com https://doi.org/10.1530/EC-20-0211 (c) 2020 The authors Published by Bioscientifica Ltd

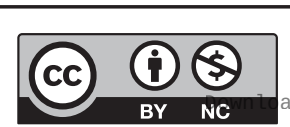

This work is licensed under a Creative Commons Attribution-NonCommercial 4.0 International License. ded from Bioscientifica.com at 04/26/2023 08:29:18AM 
intravenous infusion of interleukin-2 in the immunotherapy of cancer. Anticancer Research 199010 753-757.

30 Lotze MT, Frana LW, Sharrow SO, Robb RJ \& Rosenberg SA. In vivo administration of purified human interleukin 2. I. Half-life and immunologic effects of the Jurkat cell line-derived interleukin 2. Journal of Immunology 1985134 157-166.

31 Spinazze S, Viviani S, Bidoli P, Rovelli F, Palmer P, Franks CR, Arienti F, Rivoltini L \& Parmiani G. Effect of prolonged subcutaneous administration of interleukin-2 on the circadian rhythms of cortisol and beta-endorphin in advanced small cell lung cancer patients. Tumori 199177 496-499. (https://doi. org/10.1177/030089169107700609)

32 Turnbull AV \& Rivier CL. Regulation of the hypothalamic-pituitaryadrenal axis by cytokines: actions and mechanisms of action. Physiological Reviews 199979 1-71. (https://doi.org/10.1152/ physrev.1999.79.1.1)

33 Barkhudaryan N \& Dunn AJ. Molecular mechanisms of actions of interleukin- 6 on the brain, with special reference to serotonin and the hypothalamo-pituitary-adrenocortical axis. Neurochemical Research 199924 1169-1180. (https://doi. org/10.1023/A:1020720722209)

34 Spath-Schwalbe E, Hansen K, Schmidt F, Schrezenmeier H, Marshall L, Burger K, Fehm HL \& Born J. Acute effects of recombinant human interleukin- 6 on endocrine and central nervous sleep functions in healthy men. Journal of Clinical Endocrinology and Metabolism 199883 1573-1579.

35 Stouthard JM, Romijn JA, Van der Poll T, Endert E, Klein S, Bakker PJ, Veenhof CH \& Sauerwein HP. Endocrinologic and metabolic effects of interleukin-6 in humans. American Journal of Physiology 1995268 E813-E819.

36 Berkenbosch F, van OJ, del RA, Tilders F \& Besedovsky H. Corticotropin-releasing factor-producing neurons in the rat activated by interleukin-1. Science 1987238 524-526. (https://doi.org/10.1126/ science.2443979)

37 Hanisch UK, Rowe W, Sharma S, Meaney MJ \& Quirion R. Hypothalamic-pituitary-adrenal activity during chronic central administration of interleukin-2. Endocrinology 1994135 2465-2472. (https://doi.org/10.1210/endo.135.6.7988433)

38 Matta SG, Weatherbee J \& Sharp BM. A central mechanism is involved in the secretion of ACTH in response to IL-6 in rats: comparison to and interaction with IL-1 beta. Neuroendocrinology 199256 516-525. (https://doi.org/10.1159/000126269)

39 Perlstein RS, Whitnall MH, Abrams JS, Mougey EH \& Neta R. Synergistic roles of interleukin-6, interleukin-1, and tumor necrosis factor in the adrenocorticotropin response to bacterial lipopolysaccharide in vivo. Endocrinology 1993132 946-952. (https:// doi.org/10.1210/endo.132.3.8382602)

40 Spath-Schwalbe E, Born J, Schrezenmeier H, Bornstein SR, Stromeyer P, Drechsler S, Fehm HL \& Porzsolt F. Interleukin-6 stimulates the hypothalamus-pituitary-adrenocortical axis in man. Journal of Clinical Endocrinology and Metabolism 199479 1212-1214.

41 Ray D \& Melmed S. Pituitary cytokine and growth factor expression and action. Endocrine Reviews 199718 206-228. (https://doi. org/10.1210/edrv.18.2.0297)
42 Mulla A \& Buckingham JC. Regulation of the hypothalamopituitary-adrenal axis by cytokines. Best Practice and Research Clinical Endocrinology and Metabolism 199913 503-521. (https://doi. org/10.1053/beem.1999.0041)

43 Path G, Scherbaum WA \& Bornstein SR. The role of interleukin-6 in the human adrenal gland. European Journal of Clinical Investigation 200030 (Supplement 3) 91-95. (https://doi.org/10.1046/j.13652362.2000.0300s3091.x)

44 Chrousos GP. The hypothalamic-pituitary-adrenal axis and immunemediated inflammation. New England Journal of Medicine 1995332 1351-1362. (https://doi.org/10.1056/NEJM199505183322008)

45 Lacroix S, Vallieres L \& Rivest S. C-fos mRNA pattern and corticotropin-releasing factor neuronal activity throughout the brain of rats injected centrally with a prostaglandin of E2 type. Journal of Neuroimmunology 199670 163-179. (https://doi.org/10.1016/S01655728(96)00114-2)

46 Watanobe H, Nasushita R \& Takebe K. A study on the role of circulating prostaglandin E2 in the adrenocorticotropin response to intravenous administration of interleukin-1beta in the rat. Neuroendocrinology 199562 596-600. (https://doi. org/10.1159/000127055)

47 Watanobe H, Sasaki S \& Takebe K. Role of prostaglandins E1, E2 and F2 alpha in the brain in interleukin 1 beta-induced adrenocorticotropin secretion in the rat. Cytokine $1995 \mathbf{7} 710-712$. (https://doi.org/10.1006/cyto.1995.0083)

48 Liu PY. A clinical perspective of sleep and andrological health: assessment, treatment considerations, and future research. Journal of Clinical Endocrinology and Metabolism 2019104 4398-4417. (https:// doi.org/10.1210/jc.2019-00683)

49 Iranmanesh A \& Veldhuis JD. Hypocortisolemic clamp unmasks jointly feedforward- and feedback-dependent control of overnight ACTH secretion. European Journal of Endocrinology 2008159 561-568. (https://doi.org/10.1530/EJE-08-0417)

50 Roelfsema F, Yang RJ, Olson TP, Joyner MJ, Takahashi PY \& Veldhuis JD. Enhanced coupling within gonadotropic and adrenocorticotropic axes by moderate exercise in healthy men. Journal of Clinical Endocrinology and Metabolism 2017102 2482-2490. (https://doi.org/10.1210/jc.2017-00036)

51 Roelfsema F, Pereira AM \& Veldhuis JD.Impact of adiposity and fat distribution on the dynamics of adrenocorticotropin and cortisol rhythms. Current Obesity Reports 20143 387-395. (https://doi. org/10.1007/s13679-014-0118-7)

52 Hughes KA, Manolopoulos KN, Iqbal J, Cruden NL, Stimson RH, Reynolds RM, Newby DE, Andrew R, Karpe F \& Walker BR. Recycling between cortisol and cortisone in human splanchnic, subcutanuous adipose, and skeletal muscle tissues in vivo. Diabetes $2012 \mathbf{6 1}$ 1357-1364. (https://doi.org/10.2337/db11-1345)

53 Garbe C, Eigentler TK, Keilholz U, Hauschild A \& Kirkwood JM. Systematic review of medical treatment in melanoma: current status and future prospects. Oncologist 201116 5-24. (https://doi. org/10.1634/theoncologist.2010-0190)

54 Posadas EM, Limvorasak S \& Figlin RA. Targeted therapies for renal cell carcinoma. Nature Reviews Nephrology 201713 496-511. (https:// doi.org/10.1038/nrneph.2017.82)

Received in final form 25 May 2020

Accepted 8 June 2020

Accepted Manuscript published online 9 June 2020 https://ec.bioscientifica.com https://doi.org/10.1530/EC-20-0211 (c) 2020 The authors Published by Bioscientifica Ltd

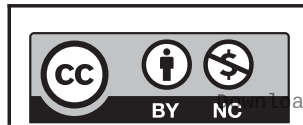

This work is licensed under a Creative Commons Attribution-NonCommercial 4.0 International License. ded from Bioscientifica.com at 04/26/2023 08:29:18AM 